\title{
Introduction to European Journal of Burn Care
}

\author{
Juan P. Barret ${ }^{1,2}$ \\ 1 Department of Plastic Surgery and Burns, Hospital Universitari Vall d'Hebron, 08035 Barcelona, Spain; \\ jpbarret@vhebron.net \\ 2 Department of Surgery, School of Medicine, Universitat Autònoma de Barcelona Passeig de la Vall d'Hebron \\ 119-129, 08035 Barcelona, Spain
}

Received: 12 August 2019; Accepted: 15 August 2019; Published: 20 August 2019

check for updates

Burn injuries are one of the most severe forms of trauma that a human being may suffer. They are an injury to the skin or other organic tissue primarily caused by thermal or other acute trauma. Once a burn has occurred, it induces a complex cascade of various responses including inflammatory, hypermetabolic, immune, infectious, and psychosocial responses. These responses interact with each other and are extremely complex and difficult to treat. Burn care has been organized in specialized centres capable to deliver state of the art treatment merging the expertise of different medical and non-medical disciplines centred in one goal: to treat, heal, and reintegrate the patient back into society. Significant advances have been produced during the last years, which include the burn centre concept, advances in shock and resuscitation, wound care and infection, burn surgery, inhalation injury and pulmonary care, nutrition, rehabilitation, and reconstruction. However, not only is extensive research in the acute phase response necessary, but also outcome analysis and psychosocial recovery are of upmost importance [1,2].

The burden of burns in the world is overwhelming. Burn injuries are a public health problem and most, if not all of them, are preventable. Prevention means anticipation and it has become the goal of modern Medicine. It is the more efficient way to treat illness. However, it requires data, epidemiological studies and risk factor research studies. Globally, burns are a serious public health problem. According to the World Health Organization, an estimated 265,000 deaths occur each year from fires alone, with more deaths from scalds, electrical burns and other forms of burns, for which global data are not available. In addition to those who die, millions more are left with lifelong disabilities and disfigurements, often with resulting stigma and rejection. A recent report points out that more than five billion people in the world lack any emergency surgical support whatsoever. This is a moral imperative that remains unsolved [3].

It is a great pleasure to welcome you to the European Journal of Burn Care (EJBC). The journal is owned by the European Burns Association (EBA) and shares the same common goals of the association: Spreading knowledge of and stimulating prevention in the field of burn injury; promoting international disaster planning; facilitating the exchange of ideas and expertise; encouraging research into scientific, clinical and social aspects of burn injury; promoting education in all aspects of burn injury, including first aid, nursing and rehabilitation (both physical and phycological); facilitate and promote guidelines and recommendations on burn care, and the provision of burn care in practice [4]. The European Burns Association is the highest learned association devoted to burns in Europe. It joins together all individuals and national associations with an interest in burns with the common goal of burn prevention, reintegration of the burn victim into society and to promote the advancement of burn care. One of the most important tasks of EBA is the development of the European Guidelines for Burn Care Provision, which also recommends the Minimum European Level of Burn Care Provision (4). Clinical practice guidelines or protocols are currently a regular part of a clinician's armamentarium. Thy are constantly upgraded on a regular basis and expanded when necessary. They level the standard of care among hospitals and nations, while understanding the local scenario and cultural differences. 
Europe is a continent moving towards unification, including in Medicine. Open borders allow European citizens and health personnel to move freely. Similarly, knowledge moves even faster and unifies academic standards. In a united Europe, minimal standards are a must, and the former also applies to burn care. The EBA Burn Centre Verification Program allows to standardize the minimal requirements of care for patients and helps all participating members to develop and implement the guidelines or to work towards such standards with the help of the Association when and where necessary.

Burn Care should be considered a "central health science": it joins different health related disciplines in clinical practice, scientific research, and prevention. It trespasses the clinical scenario and reaches different backgrounds, from burn care in practice to materials science research and molecular biology. It is important to have platforms which allow researchers to address the broader community. Indeed, many of the most interesting and paradigm-shifting results come from research activities between established disciplines.

I firmly believe that the better we communicate between ourselves, inside and outside our disciplines, the better mankind can benefit from our research. I am proud and honoured to be Editor-in-Chief of this new journal dedicated to publishing ground-breaking results from the entire field of burn care. I will of course be delighted to see interdisciplinary research, but I will particularly welcome outstanding results from disciplines presented in a way that the wider health-related community can appreciate and assimilate them. All of us who work in burn care are one, but each of us must learn from the others. In this context, the training of future generations of practitioners and scientists is paramount, and submissions in the area of burn care education, burn centre organization, and provision of care will be highly appreciated. Similarly, we have to remember that our responsibility as health care workers is to treat other human beings with empathy and compassion in order to provide them with the strength to carry on and recover from illness. In this perspective, I would also welcome submissions on ethics, philosophy, and humanitarian aspects of burn care.

Finally, it is a great honour to be associated with a burn care journal that is predicated upon the principles of Open Access publication. The need for the results of public-funded research to be available to the whole of society is an imperative that I embrace and welcome, even though it is predicated upon changes in traditional publishing strategy and practice. I look forward to bringing the research excellence of burn care and research to a broader audience.

It goes without saying that all this was made possible by the enthusiastic support of past and present EBA executive committee members, Congress Care staff, and the support that the Multidisciplinary Digital Publishing Institute (MDPI) provided to our organization.

As Editor-in-Chief I would like to encourage all interested scientists, clinicians, and practitioners related to Burn Care worldwide to submit their research to this exciting new journal. Together with our Associate Editors and the whole Editorial Board, I am looking forward to contributing to the inevitable success of the European Journal of Burn Care.

Conflicts of Interest: The author declares no conflict of interest.

\section{References}

1. Greenhalgh, D.G. Management of Burns. N. Engl. J. Med. 2019, 380, 2349-2359. [CrossRef] [PubMed]

2. Finnerty, C.C.; Jeschke, M.G.; Branski, L.K.; Barret, J.P.; Dziewulski, P.; Herndon, D.N. Hyperthrophic scarring: the greatest unmet challenge after burn injury. Lancet 2016, 388, 1427-1436. [CrossRef]

3. WHO. Burns; WHO: Rome, Italy, 2018; Available online: https://www.who.int/en/news-room/fact-sheets/ detail/burns (accessed on 10 August 2019).

4. European Burns Association. Available online: https://www.euroburn.org/documents/ (accessed on 10 August 2019). 